\title{
Investigating the Use of the Experience Clip Method
}

\author{
Jeroen Vanattenhoven and Dries De Roeck \\ Centre for User Experience Research, IBBT / KU Leuven, \\ Parkstraat 45 Bus 3605, 3000 Leuven, Belgium \\ \{jeroen.vanattenhoven, dries.deroeck\} @soc.kuleuven. be
}

\begin{abstract}
The focus of this paper is on the use of the Experience Clip method for evaluating mobile applications. In this method one participant uses the tobe-evaluated mobile application while the other participant films whatever happens during the field test. Afterwards, participants are interviewed by the researcher(s) to clarify the recorded situations. Investigating the use of the Experience Clip method was achieved by evaluating two mobile multimedia geocaching applications. The method was found very suitable for capturing rich, emotional user experiences and uncovering usability issues. Furthermore, digital photo cameras, used by participants for filming, offer great image quality, ease-of-use, sufficient storage capacity, and attract little attention of bystanders. However, there is one concern that when participants film each other, another experience is added on top of the experience with the mobile application. It is unclear how the filming experience affects actual use and the validity of the collected data.
\end{abstract}

Keywords: User Experience, Mobile Computing, Geocaching, Evaluation, Experience Clip, Tangible Interaction.

\section{Introduction}

Evaluating mobile applications still involves several challenges. Currently, different methods exist to evaluate mobile applications such as diaries, questionnaires, mobile labs, logging, ESM, shadowing, etc [1][3]. Recently, Experience Clips was presented as a new way to evaluate mobile applications [2][3]. This method involves two participants who preferably know each other. One participant uses the application, while the other one shoots video clips - "Experience Clips" - to document the user's experiences and emotions. Halfway in each field test the user takes over the role of the shooter and vice versa, so both participants have used the application, and both participants have created Experience Clips. Afterwards both participants are invited to talk about their experiences using the videos they recorded. The main benefits are that the captured experiences are more natural because the researcher is not following or shadowing the participants, and that the participants already know each other. Furthermore, the elicitation afterwards is helped by the fact that one relies less on memory because the video captures the activity as it unfolds. 
Geocaching "is the practice of hiding a container in a particular location, then publishing the latitude and longitude coordinates of the location on a geocaching web site for other geocachers to find using a GPS device" [4]. Some caches involve intermediate locations before getting to the cache, and involve puzzles that have to be solved in order to get to the end result. The evaluated applications have made use of the possibilities of mobile technology (GPS, pictures, video, audio and music), to augment such a geocaching experience.

In this paper we first describe the applications and their features. We continue by presenting the participants and the procedure, followed by the analysis and results of the user experience and usability evaluation. Finally, we discuss the most significant issues in using the Experience Clip method, formulate the main conclusions and identify future work.

\section{User Experience Evaluation}

\subsection{Applications}

The application referred to as 'Fluisterdingen' was developed as part of the ITEA SmartTouch project by Alcatel-Lucent Bell Labs and globally allows users to share media via NFC technology through RFID tags. Fluisterdingen consists of an online editor for PC and a mobile phone application. Only the latter was included in the user study. The online editor was used by the research team to create a route through the city centre of Leuven which consisted of five points of interest. Each point of interest was marked with a cardboard indicator that had an RFID tag on it (Fig. 1). Users had to find this tag and physically touch it with the phone in order to receive a description and a picture that contained hints about their next location. This application ran on a Nokia 6131 mobile phone (Fig. 1).

The 'Mediacaching' application was developed by researchers of the University of Cologne in the CITIZEN MEDIA research project, and is a multimedia geocaching application that incorporates Semacodes, GPS, audio, pictures, video and 3D models. Users can create their own geocaches with the online editor (http://www.mediacaching. org). We used this editor to create a route for the user experience evaluation in the city centre of Leuven. After the application started, the user would receive a hint to their first location. This hint could either be composed of text, pictures, video, audio, and a GPS-driven location indicator. When the user arrived at the location, an assignment would have to be carried out. One of the assignments in our study was answering a question (multiple choice, multiple selections) and providing evidence to that question using the camera on the phone. Another assignment was that the participants had to create a short clip that could serve as an item on the evening news. After the assignment they would receive the hint to the next location. When participants completed the tour, they received a "treasure"; in our case, a fireworks movie. This application ran on a Nokia N95 mobile phone (Fig. 1). 


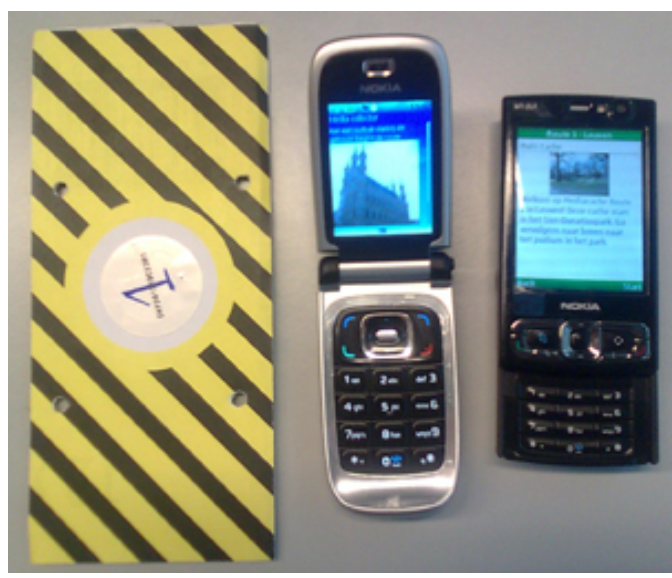

Fig. 1. RFID tag, Fluisterdingen application, and Mediacaching application

\subsection{Participants and Procedure}

Participants were recruited via a mailing list. Six student couples participated; one male couple, one mixed couple and four female couples. All couples knew each other or were friends. An incentive was provided in the form of a coupon of $20 €$ for a multimedia store in Belgium.

Participant couples were invited to the research centre where they were briefed about the study which included an explanation of how to use the applications and the digital photo camera, how to shoot experience clips and what to film, and were to go [2]. One of the participants carried the application while the other carried a digital photo camera (Panasonic Lumix with a 2GB SD Card). They were also asked to switch half-way during the test so both participants would have used the application and would have created experience clips.

Both applications were evaluated; for each application we foresaw a briefing of approximately 5-10 minutes, a field test using Experience Clips for 30 minutes, and an interview afterwards about participants' experience clips, making the total evaluation time one hour. Hence, the evaluation of two applications by one couple took approximately two hours. Three of the couples started with the Fluisterdingen application; the other three couples evaluated Mediacaching application first.

\subsection{Analysis and Results}

When investigating the use of the method, it is important to look at how the method is able to fulfill its purpose: evaluating user experience and usability of mobile applications. Therefore, in this section the analysis is described, followed by the results of the usability and user experience evaluation. More specifically, we first present the most significant usability issues and participants' experiences with the evaluated applications; then we discuss the evaluation of the devices itself.

The Experience Clips are transcribed into an "action-table" containing three columns (Table 2) [2][3]. The first two columns contain the transcription of the 
dialogue between the two participants; in the third column a description is given about what is shown on the video, and what is happening in the field. We incorporated two more columns to add the transcriptions of the interviews about the experience clips with the participants after they returned from their field test. What a participant and researcher said in the interview, was placed exactly at the same line of the respective moment in the action table of the experience clip. In this paper however, we will not be able to present five columns because of a lack of horizontal space. This provided us with an overview on what happened during the field test and what was said during the interview afterwards. These action-tables formed the basis for the analysis, together with the video data. The interviews were semi-structured and inquired about what they liked and disliked about the application, the device, and the filming of the experience clips.

We collected 123 videos in total (see Table 1); a total duration of 36 minutes and 49 seconds for the Mediacaching application, and 15 minutes and 12 seconds for the Fluisterdingen application. Average length per video was 28 seconds for Mediacaching and 20 seconds for Fluisterdingen, while the median length was 22.5 seconds for Mediacaching and 12 for Fluisterdingen. The shortest videos for Mediacaching and Fluisterdingen were one second long, the longest Mediacaching video was two minutes and 51 seconds long whereas the longest Fluisterdingen video was 58 seconds long.

Table 1. Number of videos per application

\begin{tabular}{|l|l|l|l|l|l|l|l|}
\hline Participant couple & 1 & 2 & 3 & 4 & 5 & 6 & Total \\
\hline Mediacaching & 17 & 21 & 9 & 6 & 12 & 13 & 78 \\
\hline Fluisterdingen & 6 & 7 & 17 & 5 & 4 & 6 & 45 \\
\hline & & & & & & Total & 123 \\
\hline
\end{tabular}

There were several usability issues with the Mediacaching application; only one problem was found with the Fluisterdingen application - the RFID tag did not always register immediately upon touching it with the mobile phone. One of the main problems in the Mediacaching application was the GPS-driven location indicator. Participants were confused by the fact that the indicated direction in which they were supposed to walk changed quite often, and did not know that they did not had to walk until the meter counter (that counted down towards the next destination) reached zero. The longest video, two minutes and 51 seconds, was a result of these problems, and all participant couples experienced this problem. To add to the problem, the message "walk faster" was shown simultaneously, because the direction based on GPS could only be calculated if users were moving. However, users were not informed that the direction based on GPS only worked this way. Another usability problem with the Mediacaching application was the screen in which participants has to select one of the multiple choice options. They would move the cursor down to their preferred answer and then press the right softkey on the mobile phone which would then process the answer ("OK" in the application). The problem was that none of the participant couples first selected the answer using the central button on the mobile phone. Most 
participant couples later found out what they did wrong, but were always surprised at first when the application informed them that their answer was wrong. In the end only two couples completed the entire route of the Mediacaching application.

The videos illustrated the user experiences to a great extent. However, to clarify the participants' meaning of the videos to the researcher(s), the interviews afterwards were really necessary. Frustration was one of the emotions we saw a lot on the clips mainly due to usability problems. Furthermore, enjoyment was also seen several times. One good example is illustrated by the experience clip illustrated in Table 2 and Figure 2, where participants first have some difficulties in registering the RFID tag, but then succeed in finding the final location. For the Fluisterdingen application participants liked the fact that they had to touch the RFID tags, and the trembling of the mobile phone that followed, in other words, the tangible interaction. This was illustrated in some experience clips, and mentioned by all participants in the interviews. The Mediacaching application incorporated many different features such as multiple choice questions, GPS guidance, video and photo assignments etc. This variety was very much appreciated by participants in comparison with Fluisterdingen because with the latter the only interaction took place at each point-of-interest - no interaction was provided in-between. The fact that participants were active more frequently with the Mediacaching application, and were confronted with more usability problems, form the main reasons for the difference in number and length of experience clips, as indicated during the interviews.

Table 2. Experience clip illustrating enjoyment

\begin{tabular}{|c|c|c|}
\hline Application user & Video shooter & Description \\
\hline \multirow[t]{2}{*}{ Yeey! } & & $\begin{array}{l}\text { The user has found the final RFID tag. } \\
\text { The shooter films the user from behind } \\
\text { while walking toward the RFID tag. }\end{array}$ \\
\hline & $\begin{array}{l}\text { Now what? Now } \\
\text { what? Now what? }\end{array}$ & $\begin{array}{l}\text { The shooter is very excited and impatient } \\
\text { when she asks the user to explain what is } \\
\text { happening now. }\end{array}$ \\
\hline \multirow[t]{2}{*}{ It doesn't do anything. } & & $\begin{array}{l}\text { The user tries to put the mobile phone } \\
\text { against the tag; but the application } \\
\text { doesn't register the tag immediately. }\end{array}$ \\
\hline & Did it tremble? & $\begin{array}{l}\text { The shooter asks whether the mobile } \\
\text { phone trembled, something that happens } \\
\text { when the tag is registered. }\end{array}$ \\
\hline \multirow[t]{2}{*}{$\begin{array}{l}\text { Yes, but it doesn't show } \\
\text { anything }\end{array}$} & & $\begin{array}{l}\text { The shooter goes to the user and grabs the } \\
\text { mobile phone to inspect what is } \\
\text { happening. }\end{array}$ \\
\hline & $\begin{array}{l}\text { Yes but you did } \\
\text { "thingy". It's busy. }\end{array}$ & \\
\hline \multirow[t]{2}{*}{$\begin{array}{l}\text { Bullseye! You have } \\
\text { completed this route. }\end{array}$} & & The user reads the final message out loud. \\
\hline & $\begin{array}{l}\text { Perform a "round } \\
\text { dance". }\end{array}$ & $\begin{array}{l}\text { The shooter ask the use to dance around. } \\
\text { Then the shooter also dances around. }\end{array}$ \\
\hline
\end{tabular}




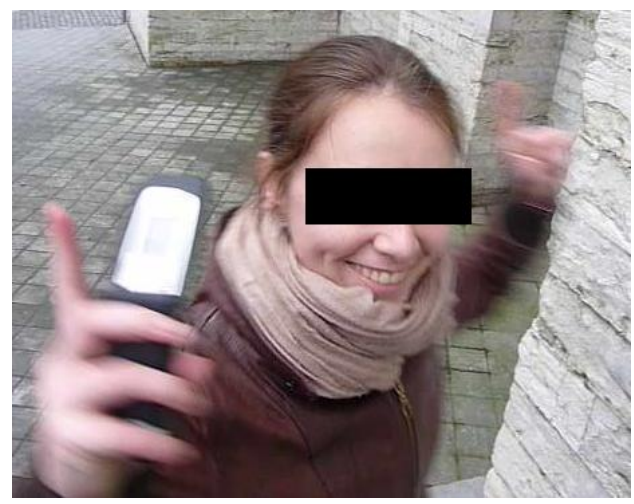

Fig. 2. Participant performing a "round dance"

We asked participants' opinions on the two different mobile used in the user study. There was a small issue with the Fluisterdingen application in that it did not always register the tag immediately. This could be seen on the Experience Clips when participants tried several positions and interactions to get the application to register the tag. There was a more severe issue with the Mediacaching device, the Nokia N95. When this device is held horizontally, the display changes from portrait to landscape. For all participants this happened quite often, and especially very unexpectedly.

\section{Discussion on the Use of the Method}

In this section we will discuss the use of the method. First, we look at how the method is able to achieve its main objective: evaluating the user experience and usability of mobile applications. The previous section on the results of the user study illustrates that the applying the method provides us with an adequate view on the usability issues, and on participants' experiences. The user study generated rich data by means of video clips, which illustrated what happened during the field study, and the interviews afterwards, in which participants clarified the recorded situations to the researchers who were not present, and therefore missed some context.

Moreover, when we compare the user experience of both applications our findings illustrate some temporal aspects of user experience. The tangible interactions with the RFID tags of the Fluisterdingen application were found very enjoyable. But our participants preferred to be entertained between the locations as well. The variety of technologies available in current mobile devices, such as GPS, RFID, Semacodes, and features such as multimedia questions and assignments in the Mediacaching application provided participants with sufficient interaction between the points of interest, in other words, a more continuous user experience.

An essential part of the Experience Clip method is the fact that participants have to walk and film each other in public. Therefore, we asked participants how they felt about this during the interview afterwards. All participants did not mind filming each other, although not all of them were completely comfortable, mainly because sometimes they felt being watched. We also asked if they would film using a mobile 
phone, as in the original work [2], or using a digital video camera. None of the participants would film using a digital video camera because they expected that this device would be harder to use and control, and because of its size, the device would attract even more attention, making it very uncomfortable. Participants would not mind using a mobile phone camera to film, but noted that, based on experience with their personal mobiles, video quality on mobile phone cameras is insufficient.

There is one important methodological issue to consider: does the filming experience influence the application experience? Participants were free to film as they saw fit; one couple was acting (performing) in front of the camera and created mini plays, presenting their experiences to the researchers. The other couples mostly logged the behavior of the user, while engaging in dialogue with them at certain points. The researchers that originally developed the method are aware of this performance aspect, but discussed it mainly as an opportunity for participatory design [2][3]. What the impact of the filming experience is on the use of the application, and the validity of the results, remains unclear. One important strength of this method, and an important issue in evaluation mobile applications, is that rich data can be gathered from users in the field, with minimal intrusion from researchers. If one considers the creation of mini plays by participants, the possibility that this is done to seek approval from the researchers might impact the strength of the method.

Because two people are involved in this method, it is not straightforward to capture individual experiences and opinions. On the other hand, this might not be that important since the tested applications were designed to be used by multiple people, as "social walking" is one of the motivations for geocaching [4].

The audio of the videos participants made, was acceptable most of the time, but due to noises in the city environment i.e. cars passing by or the strong wind at the time of the study, at times we could not understand what participants were saying. The inaudible parts on the videos were very limited however, so it did not impact the results that much. Moreover, since the videos helped the participants' elicitation afterwards during the interviews, they were sometimes able to recall what they were saying during the inaudible parts.

The use of the digital photo cameras was found appropriate for filming each other. Using this kind of device instead of a mobile phone camera (as in the original studies [2][3]) or a digital video camera offered advantages for both participants (easy-to-use, does not attract too much attention from bystanders, sufficient storage capacity), and researcher (good video quality).

\section{Conclusion and Future Work}

The objective of this paper was to investigate the use of the Experience Clip method. We found that applying this method resulted in a rich view on participants experiences' and uncovered several significant usability issues. The resulting video is rich, and helped participants' elicitation in the interviews afterwards, which served to clarify the recorded situations to the researchers. The results of the user study allows us to improve the design of the application, and compare both applications with each other. 
More research should be carried out to investigate the differences between the devices used for filming the experience clips more in depth, since we only provided participants with a digital photo camera, and asked their opinion about the use of a mobile phone camera and a digital video camera. In other words, what people think about certain uses is not always identical to the actual use situation.

Most participants felt comfortable filming each other in the city centre. However, since we recruited students, it is uncertain to what extent other possible user profiles feel the same way about creating video clips in the presence of bystanders.

We believe that when one participant is filmed by the other, and they engage in dialogue to clarify to each other what is happening in each situation, a new experience is created. Future research should therefore investigate the impact of the filming experience on the actual use of the to-be-evaluated application and on the validity of the data.

Acknowledgments. SmartTouch is an ITEA-IWT (ITEA No 05024) project which ran from 2006 until 2008. The research described in this paper has been made possible by close collaboration with Alcatel-Lucent Bell Labs Belgium. The work for Mediacaching was supported by the CITIZEN MEDIA (www.ist-citizenmedia.org) research project funded by FP6-2005-IST-41. Special thanks to Thomas van Reimersdahl of the University of Cologne for providing fast technical feedback concerning the application, and colleague Christof van Nimwegen for feedback on this paper.

\section{References}

1. Carter, S., Mankoff, J.: When participants do the capturing: the role of media in diary studies. In: 23rd SIGCHI conference on Human factors in computing systems, pp. 899-908. ACM, New York (2005)

2. Isomursu, M., Kuutti, K., Väinämö, S.: Experience clip: method for user participation and evaluation of mobile concepts. In: 8th conference on Participatory design, vol. 1, pp. 83-92. ACM, New York (2004)

3. Isomursu, M., Tähti, M., Väinämö, S., Kuutti, K.: Experimental evaluation of five methods for collecting emotions in field settings with mobile applications. International Journal of Human-Computer Studies 65, 404-418 (2007)

4. O'Hara, K.: Understanding geocaching practices and motivations. In: 26th SIGCHI conference on Human factors in computing systems, pp. 1177-1186. ACM, New York (2008) 